\title{
Collado de los Jardines. Nuevas propuestas para la caracterización de su proceso histórico
}

\author{
Carmen Rueda Galán* \\ Luis María Gutiérrez Soler* \\ Juan Pedro Bellón Ruiz**
}

\begin{abstract}
RESUMEN
Se presentan los resultados relacionados con la ocupación medieval del Collado de los Jardines (Santa Elena, Jaén). Las intervenciones realizadas por Juan Cabré e Ignacio Calvo establecieron una hipótesis sobre el proceso histórico del asentamiento, la cual se ha mantenido hasta nuestros días. La destrucción continuada del sitio y el aislamiento al que estuvo sometido por parte de la propia investigación científica, centrada en el estudio de los exvotos de bronce ibéricos, han sido algunos de los factores que han ocasionado que se mantuviesen los presupuestos establecidos a comienzos del siglo $X X$.

Nuestra propuesta de revisión parte de la ejecución de una microprospección superficial y en el análisis historiográfico del conjunto de investigaciones realizadas en el mismo. La misma establece la reducción de la extensión de la ocupación ibérica frente a la documentación de un amplio asentamiento emiral en la cima y ladera sureste del Cerro del Castillo.
\end{abstract}

PALABRAS CLAVE: Microprospección, historiografía, asentamiento emiral.

Los últimos trabajos realizados en la Zona Arqueológica de Collado de los Jardines se encuadran en el contrato titulado 'Revisión y Actualización de la documentación de las Zonas Arqueológicas del Parque Natural de Despeñaperros', promovido por la Delegación Provincial de la Consejería de Cultura de la Junta de Andalucía de Jaén, y dirigido por el Dr. Luis

\begin{abstract}
This paper shows the results related to the Middle Age phase at the Collado de los Jardines (Santa Elena, Jaén). Juan Cabré and Ignacio Calvo established a hypothesis about the historical process of this settlement that still remain in our days. Some factors have influenced the persistence of their proposal: The on going destruction of the site and the lack of interest to the archaeologist, who always were focused on the study of the Iberian bronze offerings.
\end{abstract}

Our proposal is based on a microsurface survey carried out in the site and the historiographical analysis of overall works published. Both procedures have supposed the reduction of the Iberian ocupation and the location of the Emiral phase at the top and southeast side of the Cerro del Castillo.

KEY WORDS: microsurface survey, historiography, Emiral settlement.

Gutiérrez Soler, el cual se ha materializado en la Memoria de Licenciatura titulada 'Microprospección e historiografia para una nueva propuesta del proceso histórico de Collado de los Jardines' de Carmen Rueda Galán.

Este artículo pretende plasmar los resultados iniciales obtenidos de dichas intervenciones

* Centro Andaluz de Arqueología Ibérica. Campus Las Lagunillas, s/n. 2307I Jaén 
en esta Zona Arqueológica, centrando la exposición en el desarrollo de la identificación y documentación de un poblado de época emiral.

La caracterización del mismo, además de otra serie de nuevos presupuestos, manifiesta la imperante necesidad de una revisión de este sitio arqueológico desde otra perspectiva, alejada de su tradicional configuración desde el punto de vista monumental (OREJAS, 1998), en relación con la presencia de un emblemático santuario ibérico y, consecuentemente, aislada de la matriz histórica y social que lo ha generado (PARCERO et alii, 1998). Por lo tanto, dentro de los objetivos planteados en el contrato, el estudio no se ha ajustado a la revisión concreta del período ibérico, sino que mantuvo como idea central su análisis diacrónico, es decir, de toda la secuencia histórico-arqueológica representada en la Zona Arqueológica, ya que, de no hacerlo, supondría continuar con los tradicionales errores o distorsiones derivadas de la exclusividad en la observación de esta etapa y de prolongar los postulados originados de las intervenciones de principios de siglo $X X$.

Este trabajo se ha planteado estructurado en dos grandes bloques paralelos y complementarios entre sí:

- El estudio historiográfico de todos los trabajos realizados con anterioridad en este sitio arqueológico, centrando el análisis en la revisión de las excavaciones de principios del siglo $X X$, llevadas a cabo por Ignacio Calvo y Juan Cabré (CALVO y CABRÉ, 1917, 1918, 1919). Pero también el estudio bibliográfico de aspectos fundamentales en el desarrollo del propósito de la intervención, así es, por ejemplo, el interés por complementar el análisis con el estudio de los caminos tradicionales de Sierra Morena, de los exvotos ibéricos de bronce o la localización de lugares como la fortaleza de Castro Ferral, ubicada por estos autores en el entorno de Collado de los Jardines.
- El segundo bloque lo forma el estudio arqueológico, basado en la revisión, mediante prospección arqueológica superficial, de los límites propuestos en las intervenciones de Calvo y Cabré, respetados hasta la actualidad!

\section{LA MICROPROSPECCIÓN DEL CERRO DEL CASTILLO}

La Zona Arqueológica de Collado de los Jardines se localiza dentro del término municipal de Santa Elena, en la zona más septentrional de la Provincia de Jaén.

Existen dos características fundamentales que han determinado de manera clara los trabajos de prospección arqueológica: por un lado, su complicada geomorfología, que ha configurado un paisaje agreste y escarpado, cuya principal característica (en el Cerro de los Órganos y en el Cerro del Castillo) son los enormes estratos verticales de cuarcita, entre los cuales aparecen rocas más blandas y degradables que han generado formaciones de enormes crestones de roca; en segundo lugar, la presencia de expolios que merman de manera evidente las posibilidades de estudio en las zonas más afectadas, fundamentalmente, en la cueva y ladera del Santuario.

El primer contacto con la zona consistió en la realización de una prospección en extensión, con recogida selectiva de materiales, que permitió la identificación de distintas unidades de trabajo (Cerro del Castillo, Necrópolis, Santuario, Vía Romana y Muralla), que además resultó decisiva para la selección de la metodología más apropiada para cada unidad de análisis arqueológico. Esta primera revisión general del sitio ya evidenció la presencia de una fase medieval temprana, que posteriormente se identificó como emiral (con una cronología del siglo $(X)$, concentrada en la cima y ladera sureste del Cerro del Castillo.

\footnotetext{
I. Los límites propuestos coinciden con el recorrido de la identificada como muralla defensiva del oppidum ibérico de Collado de los Jardines, así como el santuario y el entorno del mismo (CALVO y CABRÉ, 1919).
} 
Desde el principio este trabajo estuvo asesorado por un equipo de topógrafos que valoraron el dispositivo técnico más conveniente para este tipo de actuación ${ }^{2}$, determinando finalmente la utilización de un sistema de topografía tradicional para el registro de unidades como el Cerro del Castillo, la vía romana y la fortificación, en lugar del sistema basado en GPS, dadas las limitaciones impuestas a la recepción de datos, vía satélite, por parte del relieve y la abundante vegetación arbórea y arbustiva.

Centrándonos en el Cerro del Castillo, el método de análisis arqueológico de este espacio consistió en una microprospección superficial con apoyo topográfico, es decir, con el registro de los restos materiales en coordenadas UTM. Para este fin, el paso inicial fue la realización de una topografía de la zona a detalle (E:I/500) que serviría como base cartográfica para planos temáticos en los que se han reflejado los diferentes elementos arqueológicos que configuran, de esta forma, los planos de muestreo (Ver Figura 2). Se trata de un método preciso y versátil, teniendo en cuenta las características de la zona, que hacían imposible desarrollar un reticulado del territorio como base de muestreo, experiencia que ha dado resultados positivos en asentamientos como Giribaile (GUTIÉRREZ, 1998) o el Santuario Ibérico de El Pajarillo (GUTIÉRREZ et alii, 1998).

El método de trabajo consistió en la ubicación de distintas bases topográficas en los puntos más altos del Cerro del Castillo, a partir de las cuales se estructuraron y articularon dos equipos de trabajo topográfico y arqueológico. De esta manera se registraron de forma sistemática el material o conjunto de materiales, los expolios y estructuras conservadas.

Para el registro sistemático se elaboró una ficha tipo que recogía aspectos tales como la fecha, el número de referencia, tipo de material, adscripción cronológica, relación espacial o no con los expolios existentes, elemento formal y un campo final de observaciones. Este tipo de registro permitiría un tratamiento estadístico posterior, además de las consecuentes lecturas en cuanto a la delimitación del poblamiento de distintas épocas.

La microprospección realizada en el poblado del Cerro del Castillo, ha evidenciado, como resultado principal, la presencia, claramente definida y delimitada, de al menos dos grandes etapas, correspondientes a los períodos ibérico y medieval, siendo ésta última la que comprende la mayoría de la extensión del cerro.

Se trataría, por tanto, de un asentamiento bastante amplio, con una superficie aproximada de 5 has, que se extendería desde la cima hacia la ladera sureste, y del que todavía se conservan restos de casas en los aterrazamientos que se disponen inmediatamente por encima del santuario ibérico. Estas estructuras responden a construcciones muy simples, de forma más o menos rectangular que en ocasiones aparecen aisladas y en otras aprovechan los cortados como paredes posteriores.

\section{INVESTIGACIONES CIENTÍFICAS, COLECCIONISMO Y EXPOLIO}

Es necesaria una mirada retrospectiva hacia aquellas intervenciones que se efectuaron en el sitio arqueológico, no con el fin de aportar una amplia documentación disponible al respecto, sino con el de dar nuevos enfoques fruto del propio desarrollo del conocimiento histórico-arqueológico.

Consideramos que dichas intervenciones generaron esquemas y teorías sobre la configuración del sitio que hasta ahora no han sido suficientemente cuestionadas, además, a ello tenemos que añadir la enorme carga específica que ha supuesto el convertirse en uno de los asentamientos más emblemáticos de la cultura ibérica $y$, dentro de ese esquema, dicha representatividad quedó materializada en dos aspectos divergentes: la destrucción del sitio

2. Informe de Revisión de las Zonas Arqueológicas del Parque Natural de Despeñaperros. T.M.Santa Elena, Jaén, 200 I. 
motivada por la búsqueda de los exvotos depositados en el santuario ibérico, es decir, el sitio, dentro de una matriz positivista, ha generado un enorme interés por los materiales aportados, hecho que ha determinado su destrucción y la consiguiente imposibilidad de un proceso de investigación que cuestionase las teorías fruto de las intervenciones previas a la destrucción.

Las primeras noticias que existen sobre Collado de los Jardines vienen acompañadas de la historia particular de esta región de Sierra Morena, relacionada con la historia de sus explotaciones mineras (GUTIÉRREZ et alli, 1998).

Es en la Cueva de los Muñecos de Despeñaperros el lugar donde, con motivo de trabajos de prospección en busca de filones metalíferos, a principios del siglo $X X$, se hallaron restos de fundiciones y numerosas figurillas de bronce. Muy probablemente fueron estos descubrimientos los desencadenantes de ese interés por la creación de una explotación minera, ya que fueron identificados como indicadores de un posible criadero metalífero (LUCAS, 1994).

Es en este contexto, cuando hace presencia Horace Sandars, ingeniero y arqueólogo inglés de la New Centenillo Mining Company. Realizó una primea exploración, consistente en un sondeo a los pies de la cueva (CALVO y CABRÉ, 1917), trabajo que quedó materializado en el primer artículo, en lengua inglesa, sobre el santuario y las tan famosas figurillas de bronce (RUIZ, 2002), publicado en 1906 y titulado"Pre-Roman Bronze Votive Offerings from Despeñaperros, in the Sierra Morena, Spain" (SANDARS, 1906).

Después de esta intervención, se conocen dos exploraciones puntuales realizadas por Enrique Mackay y Ernesto Abraham, también ingenieros de minas (CALVO y CABRÉ, 1917). En las Memorias de Calvo y Cabré, asimismo, se cita la intervención, en 1909, de Eusebio Vasco, quien excavó en el lado izquierdo del peñón situado junto a la cueva de los 'muñecos' (CALVO y CABRÉ, 1918), sin que se conozca mayor información al respecto pero que indica el objetivo común de las exploraciones: la búsqueda de exvotos de bronce.

Con la promulgación de la Ley de Excavaciones de 1911 y su Reglamento de 1912, y bajo el amparo de la Junta Superior de Excavaciones y Antigüedades, (JSEA en adelante), se le conceden a Juan Cabré, en 1914, los derechos de excavación sobre el Collado de los Jardines. En 1916, tras la cesión de sus derechos al estado, comienzan las intervenciones en este lugar, dirigidas finalmente por él mismo y por Ignacio Calvo, trabajos que se prolongarán hasta 19|8. La formación de ambos investigadores, junto al contexto histórico-político en el que se desarrollan dichas intervenciones, van a marcar de forma decisiva la configuración del esquema histórico-arqueológico de Collado de los Jardines.

La Ley de Excavaciones de 1911 supone, entre otros factores, la institucionalización de la arqueología, pero también la creación de un proyecto político que pretendía la recuperación y expansión del denominado Espíritu Nacional. Este programa nacionalista tendrá su reflejo en los trabajos desarrollados en Collado de los Jardines y en la propia persona de Juan Cabré, que se erige como el prototipo de arqueólogo metodológico y empírico, profesionalizado en el marco institucionalista de principios del siglo XX (RUIZ, 2002).

A partir de estas excavaciones se definirá la historia que acompañará a este sitio arqueológico, relacionado con el continuado hallazgo de exvotos de bronce, muy cotizados por el coleccionismo nacional e internacional ${ }^{3}$.

Directamente vinculado al devenir de continuos saqueos clandestinos está el intento, en febrero de 1917, de creación de la Sociedad Minera de San Antonio ${ }^{4}$ para explotar un supuesto yacimiento metalífero que coincidía no

\footnotetext{
3. Este santuario, al igual que el de la Cueva de la Lobera, se ha visto afectado desde su descubrimiento por acciones clandestinas en busca de los tan preciados 'muñecos'. En las Memorias de 1917, se cita por primera vez actuaciones de este tipo, cuando Calvo y Cabré denuncian la extracción fraudulenta de exvotos demandados desde el extranjero (Calvo y Cabré, 1917).

4. Sección de Minas. Expediente de Jefatura de Minas (Concesión San Antonio, Santa Elena), Archivo Histórico Provincial de Jaén.
} 
sólo con los límites del edificio del santuario (siendo el punto central de su demarcación el pozo que se localiza a los pies del abrigo), sino que incluía el denominado Cerro del Castillo.

A raíz de la aprobación de dicha concesión comienza toda una trama administrativa y política en la que participan el Ministerio de Fomento, el Ministerio de Instrucción Pública, la Jefatura de Agricultura, Minas y Montes y la JSEA. El desarrollo y el resultado de estas acciones constituyen uno de los primeros éxitos de la aplicación de la Ley de Excavaciones de 191।.

La denuncia de Calvo y Cabré ante la JSEA inició un amplio expediente administrativo que culminó en el reconocimiento, por parte de ingenieros de minas, de la inexistencia de cualquier criadero metalífero, hecho que desvelaba la auténtica intención de los solicitantes de la demarcación minera: la extracción de los cotizados exvotos ibéricos de bronce. Esto se puso de manifiesto cuando aún reconociendo el estado el derecho de los demandantes a la concesión minera impuso una serie de condiciones a la misma, que implicaban la propiedad por parte del Estado de los objetos arqueológicos que pudiesen aparecer. El propietario renunció a la concesión minera dadas las 'cargas' y limitaciones impuestas por la Jefatura de Minas y la JSEA.

Tras estas primeras intervenciones oficiales conocemos la aprobación, en 1920, de la solicitud de Sebastián Izquierdo para intervenir en Collado de los Jardines, sin que sepamos nada acerca de los resultados obtenidos (Archivo Gral. de la Administración, Sección 3, Caja I034).

Tendremos que esperar hasta la década de los años 50 para volver a tener noticias sobre intervenciones en Collado de los Jardines. Esta vez se producen en el marco de la creación de la Sección III del Instituto de Estudios Giennenses, presidida por Ramón Espantaleón, y el proyecto de creación del Museo Arqueológico Provincial de Jaén. Las excavaciones son realizadas por Rafael Casañas y Pedro del Nido (CASAÑAS y DEL NIDO, 1959).

Enmascarado en la pretensión del mejor conocimiento del sitio, el objetivo final era la recopilación del mayor número posible de exvotos para los fondos del futuro Museo ${ }^{5}$. En este caso, al igual que en otras intervenciones como la de Castellones de Ceal, La Guardia o Castellar, es evidente el desinterés teórico por analizar el sitio arqueológico en sí, aspecto que parece relegado a la creación de una colección propia para el citado museo (RUIZ, 2002). En este marco, en Collado de los Jardines, el trabajo consistió en la realización de seis sondeos, ubicados en puntos concretos en los que se esperaba el hallazgo de exvotos, teniendo como eje articulador de los mismos la carretera de Aldeaquemada ${ }^{6}$.

Se abre un gran paréntesis que se prolonga hasta 1995, con incoación del Expediente de Inscripción Específica en el Catálogo General del Patrimonio Histórico de Andalucía como Zona Arqueológica por parte de la Delegación Provincial de la Consejería de Cultura de la Junta de Andalucía, expediente elaborado por Yolanda Jiménez Morillas. Su catalogación como Zona Arqueológica está justificada y avalada no sólo por la importancia de este sitio arqueológico, como uno de los lugares clave para el conocimiento de la Cultura Ibérica, sino por la necesidad de una cobertura legal y administrativa suficiente que cuente con los medios suficientes para la lucha contra los continuos expolios y actividades clandestinas que tienen lugar en el mismo.

5. No hay que olvidar que todos los materiales recogidos durantes las campañas de excavación de 1916, 1917 Y 1918 pasaron a formar parte de los fondos del Museo Arqueológico Nacional (PRADOS, 1992).

6. Probablemente no se continuara en el santuario ni en su entorno más próximo por ser la zona más deteriorada por los continuos expolios y la posibilidad del hallazgo de las ofrendas de bronce es menor. Esto queda puesto de manifiesto cuando señalan que 'en la primera visita que efectuamos al santuario ibérico y a la vista del estado lastimoso en que se encuentra toda la vertiente que desciende desde la cueva hasta el barranco...vimos claramente la inutilidad de excavar en aquella zona...' (CASAÑAS y DEL NIDO, 1959:104-105). 
Las coordenadas finales del polígono de protección así como todos los datos administrativos se encuentran recogidos en la Base de Datos Arqueos de la Consejería de Cultura de la Junta de Andalucía.

Recientemente (200I-2002) se ha llevado a cabo una revisión, con el 'Proyecto de Elaboración de Expedientes de Catalogación Genérica de Zonas Arqueológicas de la etapa Protohistórica' $^{7}$, de algunos de los sitios protohistóricos recogidos en esta base de datos y que contenía información desfasada. En el caso de Collado de los Jardines se llevó a cabo la recogida de nuevos datos relacionados con el parcelario catastral de la zona.

\section{EL SANTUARIO IBÉRICO DE COLLADO DE LOS JARDINES. LA CREACIÓN DE UNA HIPÓTESIS PARA UN SIGLO}

Como se ha señalado anteriormente, los trabajos elaborados por Ignacio Calvo y Juan Cabré se configuran como un punto de partida imprescindible a la hora abordar cualquier tipo de actuación en la Zona Arqueológica de Collado de los Jardines. Esto es, fundamentalmente, porque se trata de las primeras y únicas intervenciones que han afrontado globalmente todo el complejo arqueológico, aún sin obviar los límites e inconvenientes propios de una excavación de principios de siglo $X X$ es necesario reconocer en su trabajo la existencia de unas detalladas descripciones, así como el uso sistemático de la fotografía como siste- ma de apoyo al registro de la excavación, la realización de inventarios, dibujos y los primeros intentos de elaboración de una secuencia basada en la estratigrafía.

Tras las excavaciones de Calvo y Cabré se conforma una secuencia histórico-arqueológica que ha permanecido con pocas variaciones hasta nuestros días. Para ellos la primera ocupación del sitio arrancaría desde el siglo IV a.n.e. y continuaría, casi ininterrumpidamente, hasta la segunda mitad del siglo XVIII.

Sin embargo, no cabe duda, es el período ibérico-romano el centro del interés de ambos autores $^{8}$, hasta el punto de que otras etapas históricas son meramente citadas sin entrar a desarrollarlas íntegramente. En época ibérica, según los autores, se establecería un gran oppidum de unas 27 has ${ }^{9}$ con una población estimada superior a los 2.000 habitantes, aunque ésta se concentraría en la zona norte, llamada por los autores 'acrópolis' 10. Esta gran 'ciudad' estaría fortificada por una muralla que rodearía sus límites, alternando sus técnicas constructivas " con los grandes accidentes geográficos que funcionarían como elementos de defensa natural, como queda puesto de manifiesto en el norte del Cerro del Castillo o el Cerro del Corzo.

Se configura, por consiguiente, como una de las ciudades ibéricas más grandes e importantes de la Alta Andalucía, siendo el principal punto de comunicación entre La Mancha y Andalucía. Es esta idea, como punto de comunicación estratégico, la que explicaría la exis-

7. Promovido por la Delegación Provincial de la Consejería de Cultura de Jaén de la Junta de Andalucía y dirigido por Juan Pedro Bellón.

8. La explicación del interés centrado en el período ibérico hay que buscarla en la necesidad de legitimación del espíritu nacionalista y por tanto de realzamiento de lo autóctono en oposición a lo extranjero. En esta línea están las constantes críticas realizadas por los autores a lo largo de sus Memorias de Excavaciones con relación a la demanda de objetos fomentada desde Francia que acabaría generando multitud de expolios, además de las distintas teorías elaboradas por autores extranjeros, como por ejemplo R. Lantier respecto al origen de los exvotos de bronce.

9. El tamaño y caracterización de este poblamiento ha sido mantenidos por autores como Almagro Gorbea (1987), sin embargo Geràrd Nicolini establece el tamaño en 4 has. (NICOLINI, 1969)

10. La utilización de esta terminología es un ejemplo de la influencia de parámetros clasicistas no sólo en cuanto a la descripción del oppidum, sino en cuanto al tratamiento del santuario que es identificado como de planta clásica (CALVO y CABRÉ, 19l8).

I।. Los autores hablan de la documentación de una muralla en talud, de unos $70 \mathrm{~cm}$. de ancho y reforzada por la excavación del foso, en la zona más débil que sería el collado. También hablan, en la Silleta del Corzo, de una gran muralla de $2 \mathrm{~m}$. de ancho, careada al exterior y levantada a plomo (CALVO y CABRÉ, I9|8). 
tencia del Santuario Ibérico. Otros elementos reforzarían su carácter monumental, como el gran farallón y el abrigo rocoso en torno a los que se dispone, su relación con fuentes de agua y bosques circundantes, identificados como elementos sagrados, enmarcándolo dentro de los esquemas conocidos de santuarios en la antigüedad (BLÁZQUEZ, 199|). De hecho, Calvo y Cabré identifican la primera fase del santuario con el uso exclusivo del bosque sagrado que actuaría como 'Templo Natural'.

La siguiente fase del santuario es fechada hacia el siglo IV a.n.e. ${ }^{12}$ y continuará hacia el siglo I d.n.e., momento en que se produce una ampliación de la zona sacra. Hacia el siglo III d.n.e. el santuario sería destruido de forma violenta, sin embargo, los autores amplían su continuidad hasta época de Teodosio.

Una vía de primer orden, que en un principio sería identificada con la Via Augustea, es decir, el principal enlace de Laminium con Cástulo, reforzaría su importancia como un sitio estratégico en las comunicaciones de la Antigüedad. De ese modo se llega a proponer su identificación con la II Masio Solaria citada en los Vasos Apolinares.

Para época medieval, sin precisar una fecha más concreta, documentaron, en la cima del denominado Cerro del Castillo, los restos de una fortificación además de 'unas galerías', que fueron identificadas, utilizando las fuentes escritas, con Castro Ferral. El lugar sería ocupado sin interrupción hasta época de Carlos III, momento en que la población se traslada a las Correderas.

En resumen, desde el punto de vista historiográfico hay que reseñar algunos elementos que nos sirven de partida para el posterior debate sobre el tipo de asentamiento documentado:
- En el desarrollo de las intervenciones realizadas a principios del siglo XX, Calvo y Cabré documentaron dos estructuras de fortificación, una localizada en la cima del Cerro del Castillo, identificada por ellos como Castro Ferral, y, por otro lado, un gran muro perimetral que bordearía el poblado y toda la zona del collado, pero entendido esta vez como la fortificación del gran oppidum ibérico que para los mismos existió en la zona (CALVO y CABRÉ, 1917, 1918 y 1919).

- Los mismos autores hacen referencias concretas a determinado tipo de material cerámico que podría ser identificado como de época emiral. Puede tratarse de ollas trípode, que constituyen en la actualidad uno de los mejores indicadores arqueológicos de la fase emiral del Alto Guadalquivir (CASTILLO, 1998).

- Por otro lado, estos investigadores supieron percibir diferencias en la distribución de las estructuras del sitio arqueológico, distinguiendo un núcleo fortificado en la cima del Cerro del Castillo, frente a un hábitat 'desestructurado', inorgánico, extendido en la ladera sureste (CALVO y CABRÉ, 1918). La cima del Cerro del Castillo pasó a ser concebida como la acrópolis de época romana, en contraposición con las casas de la ladera, las cuales son adscritas a la población indígena, una vez expulsada por los conquistadores de la cima.

\section{LAS 'FORTIFICACIONES'}

El primer punto quedó descartado, puesto que en la actualidad se conoce la ubicación exacta de Castro Ferral, localizado en el Puerto del Muladar, sobre un cerro al sur de la Peña de Malabrigo, cerca del Arroyo de Navalquejigo y por tanto muy al oeste de Collado, al otro lado del desfiladero (ESLAVA, 1999). En cuanto a la cronología de esta fortificación debe-

12. Geràrd Nicolini (NICOLINI, 1969) retrasa, basándose en el estudio tipológico y formal de los exvotos de Collado de los Jardines, la fecha de fundación del santuario a finales del siglo VII a.n.e., cronología que coincide con la propuesta por Lourdes Prados (PRADOS, 1999) quien alude a la posibilidad, estudiando los exvotos en forma de jinete, de que la primera fase de culto se identifique con un culto de tipo heroico. 
mos señalar que en una reciente visita pudimos observar en superficie restos de materiales de época almohade y algunos cristianos, además de una moneda acuñada en tiempos de Alfonso VII (| |26-| | 57).

Con respecto a la documentación del muro perimetral, tras realizar este análisis y delimitar el trazado del mismo, se nos abre un gran abanico de posibilidades referentes a la funcionalidad y adscripción cultural del mismo. Nos decantamos a rechazar la hipótesis que afirma su constitución como fortificación del oppidum de época ibérica. Para llegar a esta conclusión nos apoyamos, en primer lugar, en la desestimación de la existencia de este gran oppidum en esta zona, además, desde el punto de vista topográfico, su propia estructuración no responde favorablemente a un elemento defensivo, ya que quedan gran cantidad de zonas desprotegidas. Otra posibilidad es que su carácter sea simbólico, es decir, que se trate de un elemento de delimitación del espacio sagrado del santuario (períbolos), sin embargo, tanto en el plano topográfico de Calvo y Cabré (19|8), como en el posterior croquis elaborado por Geràrd Nicolini (1969), la propia edificación sacra quedaría fuera de los límites marcados por el mismo.

Nosotros introducimos una tercera idea: la asociación de esta estructura a época emiral y a una funcionalidad distinta a las hasta ahora atribuidas, como podría ser la posibilidad de integrar un gran redil, con el fin de 'estabular' el ganado del poblado. Esta hipótesis la apoyamos en el carácter principalmente aldeano de la comunidad establecida en esa época, que, de forma muy probable explota los recursos asociados al saltus, fundamentalmente forestales y ganaderos, y posiblemente establezcan y delimiten la zona de explotación más inmediata, hecho que ha quedado constatado en otros poblados de esta misma época en la Campiña como el de las Torrecillas del Megatín (CASTILLO, 1998).
Es muy significativo el establecimiento de este asentamiento en uno de los pasos tradicionales más importantes entre la Alta Andalucía y la Meseta (CORCHADO, 1963). Por tanto, frente a las funciones netamente locales del poblado emiral, no hay que descartar la posibilidad de que el mismo se ubique en el collado con la intención de controlar dicho paso, cerrando, con el muro perimetral citado, un amplio redil que quizás supere las funciones locales antes aludidas. En este sentido, existe otro asentamiento, las Tres Hermanas, localizado en término municipal de Baños de la Encina, próximo al poblado minero de El CenteniIlo, cuyas características son similares, al encontrarse al interior de Sierra Morena pero ocupando una posición privilegiada en el entramado de caminos que comunican la sierra con la zona manchega (GUTIÉRREZ et alii, 2002: 170).

Frente a los husun-refugio descritos por Acién (ACIÉN, 1994) podría comenzar a establecerse una segunda categoría en la tipología de asentamientos, quizás en un contexto social netamente islámico y en un momento avanzado del periodo emiral, que se ubican en lugares estratégicamente ubicados y políticamente destinados al control del territorio.

\section{LOS MATERIALES}

El estudio de materiales ha dado como resultado la identificación de una etapa ibérica tardía concentrado en el entorno del santuario y en la cima del Cerro del Castillo, así como la identificación de un centro de hábitat emiral en la ladera sureste del mismo, una zona interpretada por Calvo y Cabré como ibérica (CALVO y CABRÉ,1918) y, por último, una ocupación moderna, centrada en el entorno del actual centro de recepción ${ }^{13}$.

Sin embargo proponemos, tras los resultados de la microprospección, releer las siguientes líneas de las Memorias de Excavaciones de 1918: "4a. En las casas de la población conti-

\footnotetext{
13. Esta zona se trata de la que, en las excavaciones de principios de siglo $X X$, se identificó como una 'manzana de casas de tiempos de Carlos III' (CALVO y CABRÉ, I9I8:3I).
} 
gua se han encontrado trozos de crisoles, escorias de pequeño volumen, pedazos de plomo, unos informes $y$ otros preparados en listones rayados, $y$, por último, una especie de trébedes con pies de barro." (CALVO y CABRÉ, 1918: 49). Muy probablemente esos 'trébedes' a los que hace referencia sean las ollas trípode citadas más arriba, documentadas a lo largo de nuestra intervención y asociadas a la etapa emiral (CASTILLO, 1998).

Es posible, por tanto, asociar las actividades metalúrgicas que indican los materiales y los arqueólogos J. Cabré e I. Calvo a época emiral. Con esta idea no se pretende desechar totalmente la hipótesis de que en época ibérica existiese un centro de elaboración de exvotos en este lugar, sino que se quiere introducir, dado que no se conocen datos más precisos acerca de este tema, la posibilidad de que en épocas posteriores, concretamente en la etapa emiral, se lleven a cabo refundiciones y reutilizaciones del metal de los exvotos ibéricos.

Los materiales analizados proceden de dos sistemas de trabajo: la prospección extensiva ( $18 \%$ del total de la muestra), que ha proporcionado un pequeño conjunto cerámico procedente de la primera evaluación de las distintas unidades arqueológicas $y$, por otro lado, los materiales de la microprospección del Cerro del Castillo (82\%).

Dada la imposibilidad de la realización de un estudio tipológico, por la escasez de material cerámico, se creyó conveniente su documentación gráfica y fotográfica, así como otras referencias destinadas a sistematizar su registro (Ver Figuras 5 y 6).

La totalidad de los materiales cerámicos pertenecientes al período emiral (un 62\% del total de la muestra procedente de la prospección en extensión y un 78\% derivado de la microprospección del Cerro del Castillo) se ajusta al esquema de fabricación y modelado que diferencia a este grupo de otros de épocas posteriores: su realización a mano-torneta, es decir, modelado por medio de torno intermitente aprovechando la rotación del mismo movido de forma manual. De este modo, su acabado suele ser irregular, observándose, entre otros aspectos, distintos grosores en las paredes de la pieza (CASTILLO, 1998).

Para el estudio de los materiales procedentes del Cerro del Castillo se ha utilizado como referente el amplio estudio tipológico elaborado por el Dr. Juan Carlos Castillo centrado en la Campiña de Jaén. El manejo de esta tipología como referencia se explica por varias razones: por ser un análisis de una zona muy próxima a la que está siendo objeto de estudio $y$, fundamentalmente, por la presencia de un tipo hasta ahora exclusivo del Alto Guadalquivir: la olla trípode, muy representada en la muestra obtenida en el Cerro del Castillo (GI9, G35, 666-I, I6I). Se trata de un tipo de recipiente globular que está dotada de tres apéndices en su parte inferior con la finalidad de conformar un apoyo adecuado para ser colocadas al fuego (SALVATIERRA et alii, 200I)

Otra característica general destacable de este conjunto cerámico de tradición indígena es la homogeneidad de los materiales, en los que predominan los tipos de cocina y de almacenaje, de gran tamaño. Sin embargo, a pesar de la escasez de clases, es interesante la variedad de formas dentro de un mismo tipo.

Con respecto al primer grupo, es clara la presencia de tipos definidos como el Tipo I de la Clasificación Tipológica Formal referente a vasijas cerradas, que se corresponde con ollas globulares a mano-torneta, de labio redondeado y de reducidas dimensiones. Otro tipo muy representado es la olla de labio exvasado y redondeado, con cuerpo globular, dentro del cual encontramos distintas variantes. Asimismo está presente la olla de reducido tamaño de labio exvasado con acabado en arista.

Un tipo significativo es la tinaja, con distintas variables. Dentro de este grupo se han documentado dos piezas de labio plano, cuya variación reside en el tratamiento exterior del borde de la pieza, que en un caso se presenta de forma redondeada y en el otro con acabado plano, formando, tanto al exterior como al interior del recipiente, un ángulo recto. Otra variante es la tinaja de labio redondeado. Tam- 
bién han sido documentadas orzas con labio exvasado y redondeado.

Por último quedaría hablar de las decoraciones, muy poco representativas y de tres tipos. Los dos primeros caracterizados por incisiones que responden a un esquema de bandas y trazos cortos e inclinados de forma paralela. Por último una pieza de decoración impresa de cordones.

\section{EL POBLADO EMIRAL DEL COLLADO DE LOS JARDINES}

Recordemos la visión tradicional del sitio arqueológico de Collado de los Jardines: un santuario asociado a un gran oppidum que se extendía desde el Cerro del Castillo hasta el Peñón de Corzo, fortificado y con dos necrópolis vinculadas al mismo (una intramuros y la otra fuera del límite de la muralla). En época romana sería conquistado, sufriendo nuevas modificaciones en la estructura del asentamiento de época ibérica. Para ésta etapa los autores ubican aquí a la Masio II Solaria citada en las fuentes clásicas, asociada a la identificada como Vía Augustea, que también pasaría por el mismo collado. Para época medieval, sin precisar fechas, Calvo y Cabré aluden a la localización en la cima del Cerro del Castillo, de la fortificación de Castro Ferral. Según estas teorías existiría un proceso de continuidad histórica hasta tiempos de Carlos III, trasladándose más tarde su población al núcleo de las Correderas.

En cuanto a la disposición del poblamiento, analizando las Memorias de las excavaciones, Calvo y Cabré observaron una serie de diferencias en la distribución y estructura del asentamiento, como hemos citado más arriba.

Asocian estas diferencias a modificaciones dentro del propio poblado ibérico tras la conquista romana (CALVO y CABRÉ, 19|8). Conciben un poblado romano en la cima del cerro (acrópolis) frente a otro indígena, desorganizado e inorgánico, ubicado en la ladera sureste, una vez desplazados por los conquistadores. Con toda seguridad esa diferencia radica en la confusión entre el sitio ibérico y el emiral, cuya cul- tura material no ha sido reconocida y sistematizada arqueológicamente hasta finales del siglo $X X$.

Una vez analizados elementos aislados llegaría el momento de conjugar los distintos datos aportados por los recientes estudios historiográficos y de prospección arqueológica, partiendo de la sistematización realizada por el Dr. Juan Carlos Castillo (CASTILLO, 1998) centrada en el análisis de tipos de asentamiento en la Campiña Giennense, quien se ha basado en el establecimiento de dos tipos de análisis destinados a establecer la clasificación de los mismos:

- Multivariante: aspectos como las características físicas, económicas y estratégicas cuantificables.

- Funcional: las características no cuantitativas más relevantes de los asentamientos.

En la tipología de asentamientos realizada por el Dr. Castillo, se ha establecido una categoría, cuyas características responden al esquema que hemos podido documentar en el Collado de los Jardines. Los asentamientos que ofrecen los criterios análogos más elevados son Las Torrecillas II, Cerro Peñaflor o Cerro Mortero (CASTILLO, 1998).

Los mismos han sido definidos como Husunrefugio, es decir, lugares emplazados a gran altu$\mathrm{ra}$, los cuales suelen carecer de fortificación y normalmente localizados en zonas agrestes y escarpadas, además de enmarcarse en un contexto socio-político muy determinado (ACIÉN, 1994). Es el caso del poblado del Cerro del Castillo cuya ubicación en un punto elevado y la escarpada y accidentada orografía de la zona, le proporcionan su defensa natural. Además, su cima posee un amplio control visual de todo el valle del Río Despeñaperros (Ver Figura 4). Únicamente podría cuestionarse su 'aislamiento' o su carácter de 'refugio' al encontrarse controlando uno de los pasos tradicionales de Sierra Morena.

Son asentamientos de nueva creación, en los que suele existir un fuerte componente de tradición indígena, ya que este tipo de sitios se ha 
relacionado con procesos de reestructuración de anteriores ocupaciones de época iberoromana (CASTILLO, 1998). Se constituyen como comunidades aldeanas, cuyas actividades principales son la explotación forestal y ganadera $y$, muy marginalmente, la agricultura de irrigación (Torrecillas II).

Pueden ser claramente identificados arqueológicamente con el análisis de los materiales cerámicos. Como sucede en el Cerro del Castillo, al igual que en las Torrecillas II o Cerro Mortero, los materiales se caracterizan por conformarse como un grupo homogéneo, entre los que escasea el torno y las piezas decoradas, en contraposición al desarrollo de la torneta. Con respecto a las formas y los tipos, como se ha señalado anteriormente, predominan los grandes recipientes de cocina o almacenamiento, con muy escasa variedad de formas, pero con muchas variantes dentro de una misma clase.

El Cerro del Castillo de Collado de los Jardines presenta todo este repertorio de características que lo definen como un centro emiral, de carácter aldeano y muy posiblemente dedicado a la explotación ganadera y forestal del entorno (Saltus), hecho que puede estar relacionado con la presencia de un muro de delimitación, cuya funcionalidad podría residir en la demarcación de un gran espacio de explotación y estabulación abierta perteneciente a esta comunidad.

Otra actividad muy posiblemente desarrollada en la línea de aprovechamiento de los recursos del entorno, es la refundición de exvotos, con el objetivo de reutilizar el metal. Esto, como hemos señalado anteriormente, queda puesto de manifiesto por el hallazgo, en la Campaña de 1917, de restos de escorias y exvotos mal fundidos entre el derrumbe de una casa emiral, junto a lo que hemos interpretado como ollas trípodes.

Más particularmente, centrándonos en las estructuras habitacionales, tenemos como referencia el plano topográfico realizado en 1917 , un elemento aún útil para trabajar sobre este tema, ya que lamentablemente no contamos con otro tipo de documentación en la que se deli- miten los trazados de las casas, en ese tiempo identificadas como ibéricas. Actualmente se está trabajando en la idea de realizar un plano con base topográfica en el que plasmar las unidades que aún se conservan, que, grosso modo, no suponen ni la tercera parte de las documentadas a principios del siglo $X X$.

Quizás el ejemplo más adecuado para realizar este tipo de análisis comparativo es el de Cerro de Peñaflor (SALVATIERRA et alii, 200I), no sólo por el hecho de haberse documentado una serie de estructuras domésticas comparables a las existentes en Collado de los Jardines, sino porque parece corresponder, desde el punto de vista del análisis territorial a un asentamiento del tipo del Cerro del Castillo. La organización general de este asentamiento responde a casas de gran tamaño estructuradas en torno a un patio, claramente reconocible en el conjunto de la unidad, a partir del cual se ordenan de dos a cuatro habitaciones. Su ordenación es variable, no respondiendo al esquema clásico de patio central.

Algunos de los muros sirven de medianerías con casas vecinas, además, en casi todos los casos, las casas parecen agruparse en manzanas o barrios (SALVATIERRA et alii, 200 I).

Si hacemos un zoom al plano topográfico de Calvo y Cabré (Ver Figura 3), en Collado de los Jardines se puede obtener una lectura, aunque sea parcial, de la estructuración de las unidades domésticas, observando cómo, al igual que en Peñaflor, las casas se ordenan en torno a lo que podría ser el patio y se agrupan conformando grandes unidades, que en ocasiones comparten muros.

Este poblado se ajustaría a la topografía del terreno, estructurándose mediante distintas terrazas en su ladera sureste. A este respecto podemos aludir al conjunto de muros de aterrazamiento, identificados por Calvo y Cabré como muros semicirculares de defensa del camino principal de entrada al oppidum ibérico (CALVO Y CABRÉ, 1918).

Hay una clara en la morfología de algunas de las estructuras, ya que, además de las men- 
cionadas, existen otro tipo de unidades que se construyen utilizando como apoyo los enormes crestones verticales de cuarcita (que a veces superan los 3 metros) y de las que actualmente quedan algunos vestigios en la parte alta del Cerro del Castillo.

Este tipo de centros sufrieron cambios de suma importancia, durante y después de la fitna, con el triunfo del proceso de islamización (CASTILLO, 1998). Esto conduce al planteamiento de una serie de interrogantes relativos a su continuidad o abandono durante el período califal.

El registro de materiales de la microprospección del Cerro del Castillo nos muestra alguna cerámica, muy escasa, de época islámica, sin embargo no existen suficientes indicadores que nos permitan establecer la posterior configuración del asentamiento, si bien parece claro que éste se reduce, en un momento no determinado, a la cima del Cerro del Castillo. Quizás su reocupación y su contexto socio - político posteriores estén más relacionados con el control fronterizo de la zona, contribuyendo a crear un sistema de control de los pasos tradicionales de Sierra Morena desde época almohade.

Incluso se podría introducir una tercera hipótesis, relativa a que la primera fase del castillo o atalaya, documentada muy someramente a principios de siglo y confundida con Castro Ferral, corresponda a época emiral, al momento en el que existe una necesidad de defensa y encastillamiento debido al avance de la fitna.

Aún quedaría por intentar definir si el núcleo emiral documentado en el Cerro del Castillo apareciese citado en algunas de las fuentes islámicas. En ese sentido son varias las posibles localizaciones. La primera de ellas reincide en Castro Ferral, que ha sido identificado el Hisn el 'lqáb' de las crónicas árabes (ESLAVA, 1999); sin embargo, no hemos identificado ningún indicador a este respecto en el entorno de este sitio, por lo que podría cuestionarse dicha asociación. También, según fuentes islámicas, en el entorno del Castillo de Las Navas de Tolosa, se ubicarían el castillo de los collados o de las águilas (Hins aloqbán) o el Hisn Salim según 'Abd al-Wahid' (ESLAVA, 1999).
Habría que analizar este tema más detenidamente, sin embargo, consideramos que existen suficientes indicadores que demuestran la existencia de un extenso asentamiento emiral en el Cerro del Castillo que además incorpora todas las características citadas para considerarlo como un Hins de época emiral. Pretendemos, por otro lado, iniciar una revisión del poblamiento islámico de la zona de Sierra Morena, ya que existen multitud de elementos que ponen de manifiesto su temprana ocupación.

\section{BIBLIOGRAFÍA}

ACIÉN ALMANSA, Manuel (1994): Entre el Feudalismo y el Islam. Umar Ibn Hafsun en los historiadores, en las fuentes y en la historia. Universidad de Jaén. Jaén.

ALMAGRO GORBEA, Martín (1987): "El área superficial de las poblaciones ibéricas", Coloquio Los asentamientos ibéricos ante la Romanización. 27-28 Febrero 1986. Ministerio de Cultura, Casa de Velázquez. Madrid, 21-34.

ALMAGRO GORBEA, Martín; MONEO, Teresa (2000): Santuarios urbanos en el mundo ibérico. Real Academia de la Historia, Madrid.

BLÁZQUEZ, José María (1991): Religiones en la España Antigua. Cátedra. Madrid.

CALVO, Ignacio; CABRÉ, Juan (1917): "Excavaciones de la Cueva y Collado de los Jardines (Santa Elena- Jaén). Memoria de los trabajos realizados en el año 1916", Memoria $n^{0} 8$ de la Junta Superior de Excavaciones y Antigüedades. Madrid.

CALVO, Ignacio; CABRÉ, Juan (19|8): "Excavaciones de la Cueva y Collado de los Jardines (Santa Elena, Jaén). Memoria de los trabajos realizados en el año 1917", Memoria $n^{\circ} 16$ de la Junta Superior de Excavaciones y Antigüedades. Madrid.

CALVO, Ignacio; CABRÉ, Juan (1919): "Excavaciones de la Cueva y Collado de los Jardines (Santa Elena, Jaén). Memoria de los trabajos realizados en el año 1918", Memoria $n^{\circ} 22$ de la Junta Superior de Excavaciones y Antigüedades. Madrid.

CASAÑAS, Pedro; DEL NIDO, Rafael (1959): “Prospecciones Arqueológicas en el Collado de los Jardines de Despeñaperros. 1959", Boletín del Instituto de Estudios Giennenses. $N^{\circ} 21$ (julio - septiembre). Jaén, 103-II7.

CASTILLO ARMENTEROS, Juan Carlos (1998): La Campiña de Jaén en época Emiral (S. VIII-X). Universidad de Jaén. Jaén. 
CASTILLO ARMENTEROS, J.C. (1998): "El poblamiento islámico en la Campiña de Jaén. La época emiral y el tránsito a la califal", Hispania, Al-Andalus, Castilla. Jornadas Históricas del Alto Guadalquivir. Universidad de Jaén. Jaén, |35- 158.

CORCHADO SORIANO, Manuel (1963): "Pasos naturales y antiguos caminos entre Jaén y La Mancha", Boletín del Instituto de Estudios Gienenses. No 38 (octubre- diciembre). Excma. Diputación Provincial de Jaén. Jaén, 9-37.

ESLAVA GALÁN, Juan (1999): Los Castillos de Jaén. Ed. Osuna. Granada.

GUTIÉRREZ, Luis María (1998): El poblamiento ibérico en el curso medio del río Guadalimar. Tesis Doctoral. Microfichas. Universidad de Jaén.

GUTIÉRREZ, Luis María; BELLÓN, Juan Pedro; BARBA, Vicente; ALCALÁ, Francisca; ROYO, María Ángeles y LISALDE, Rosario (1998): "Procesos históricos de asen

tamiento y sacralización de un paisaje explotado: Sierra Morena", Arqueología Espacial. No 19-20. Teruel, 283-294.

GUTIÉRREZ, Luis María; ROYO, María Ángeles; BELLÓN, Juan Pedro y BARBA, Vicente (1998): "Microprospección de superficie en el entorno del Monumento", El Santuario Heroico de El Pajarillo, Huelma (Jaén). Universidad de Jaén. Jaén, |6|-2|5.

GUTIÉRREZ, Luis María; BELLÓN, Juan Pedro; TORRES, Carmen y ARIAS, Francisco (2002): "Actuación puntual de prospección y delimitación de la zona minera de El Centenillo (Baños de la Encina, Jaén)", Anuario Arqueológico de Andalucía. II, Actividades Sistemáticas. Sevilla. 165-I75.

LUCAS PELLICER, Rosario (1994): "Historiografía de la escultura ibérica hasta la Ley de 191। (I)", Revista de Estudios Ibéricos. $N^{\circ}$ I. Universidad Autónoma de Madrid. Madrid, 15-42.

NICOLINI, Gèrard (1969): Les Bronzes Figurés des Sanctuaires Ibériques. Presses Universitaires de France. Paris.
OREJAS, Almudena (1998): "El estudio del Paisaje: Visiones desde la Arqueología", Arqueología Espacial. № 1920. Teruel, 9-20.

PARCERO, César; CRIADO Felipe y SANTOS, Manuel (1998): "La Arqueología de los espacios sagrados", Arqueología Espacial. N 19-20. Teruel, 507-516.

PRADOS TORREIRA, Lourdes (1992): Exvotos ibéricos de bronce. Ministerio de Cultura. Madrid.

PRADOS TORREIRA, Lourdes (1999): "Excavaciones de J. Cabré en el Santuario Ibérico de Despeñaperros. Un exponente de la Arqueología española de principios de siglo, La Cultura Ibérica a través de la fotografía a principios de siglo. Las colecciones madrileñas. Madrid, I03-I I0.

RUIZ RODRÍGUEZ, Arturo (2002): "De la muralla de lbros al lobo de Huelma: Jaén en la lenta construcción de una identidad para los iberos". Conferencia inaugural del Curso Académico 200 I-2002. Instituto de Estudios Giennenses, Jaén.

SALVATIERRA, Vicente (200 I): La crisis del emirato omeya en el Alto Guadalquivir. Precisiones sobre la geografía de la rebelión muladí. Universidad de Jaén. Jaén.

SALVATIERRA, Vicente y CASTILLO, Juan Carlos (199|): "El poblamiento rural: ¿Histórico o Intemporal?. El caso del arroyo del Salado, Jaén". Cuademos de Madinat Al-Zahra'. Vol. 3. Córdoba, 47-75.

SALVATIERRA, Vicente y CASTILLO, Juan Carlos (200I): Los asentamientos emirales de Peñaflor y Cerro Miguelico. El poblamiento Hispano-Musulmán en Andalucía Oriental. Campiña de Jaén (1987-1992). Monografías de Arqueología de la Junta de Andalucía, Jaén.

SANDARS, Horace (1906): "Pre-roman votive offerings from Despeñaperros in the Sierra Morena, Spain", Archaeologia, I. Oxford. 

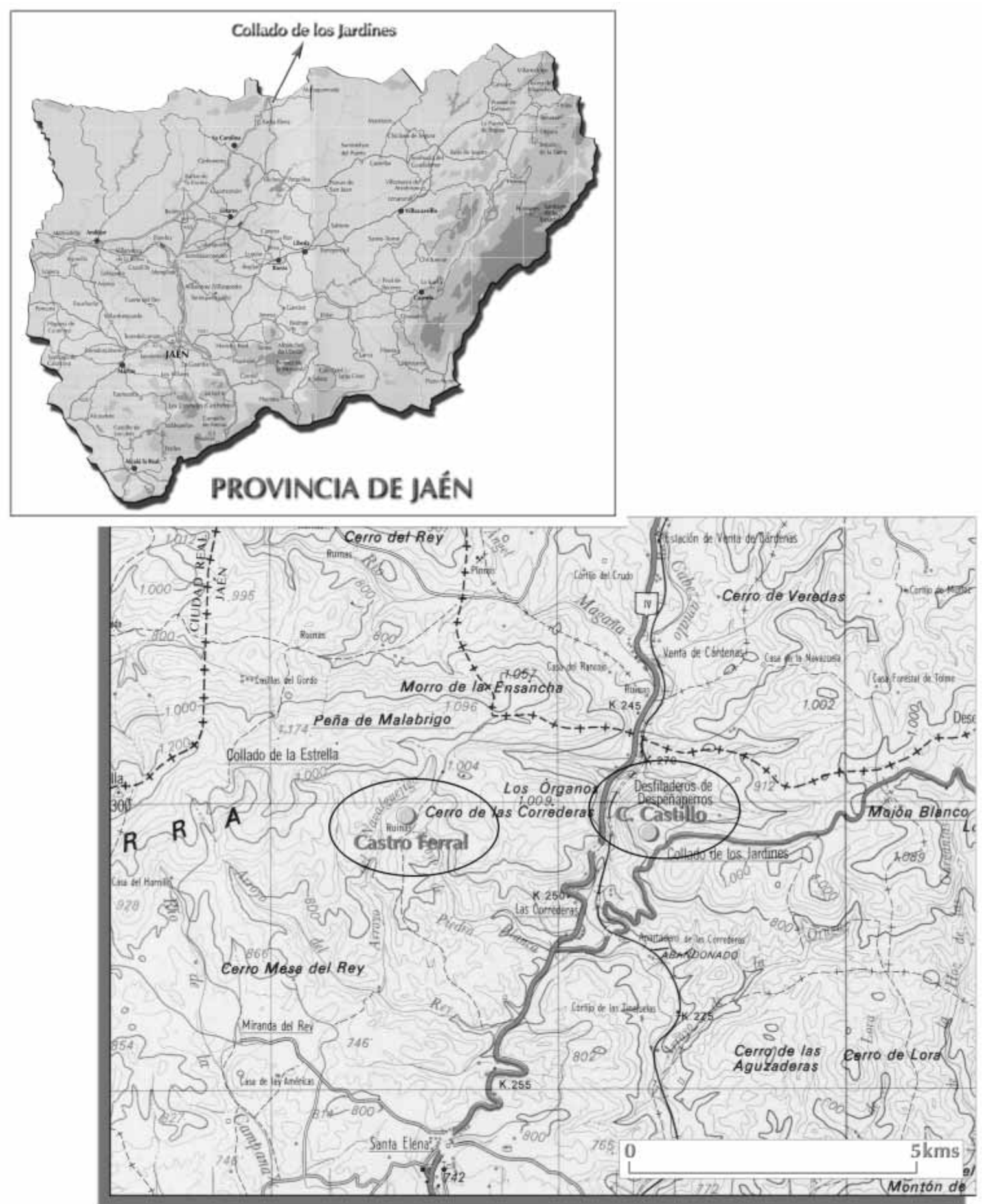

Hoja 10-17 (Santa Cruz de Mudela) Escala I//00.000. Mapa militar de España. Servicio Geográfico del Ejército. Edición 1992

Fig. I. Plano de situación en la provincia de Jaén. Localización a escala 1:100.000 


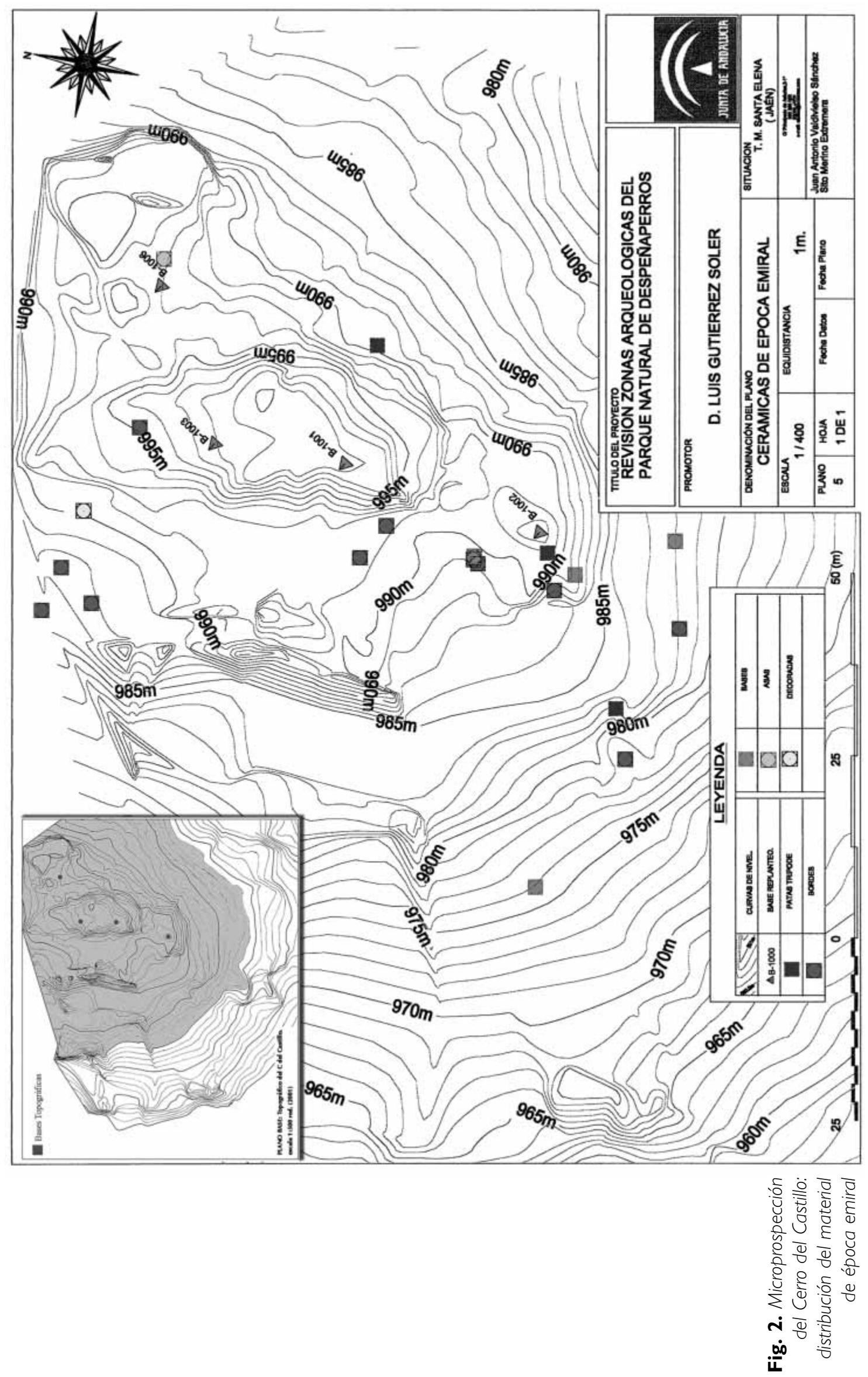




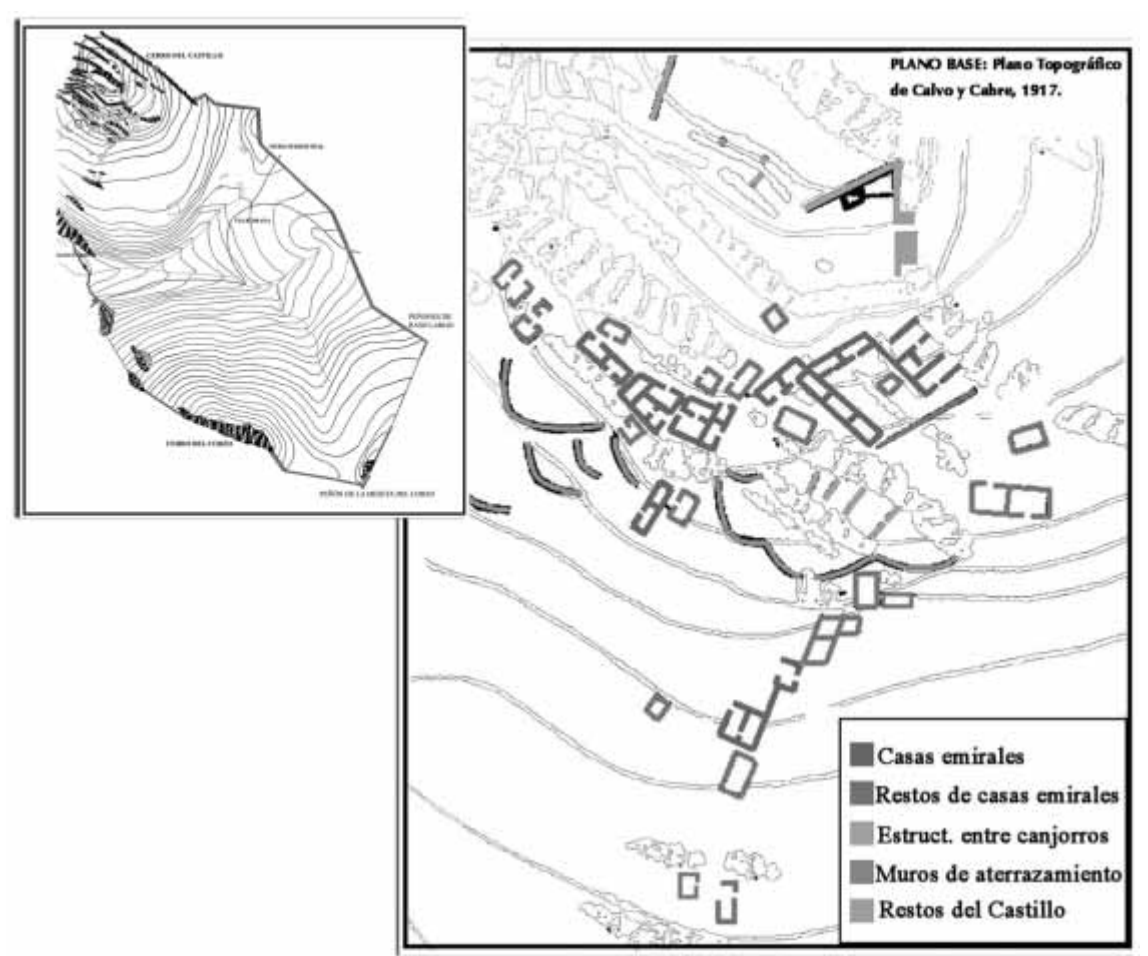

Fig. 3. Plano de comparación entre las estructuras del hábitat del Cerro del Castillo y Peñaflor

Fig. 4. Gráfico de visibilidad del Cerro del Castillo
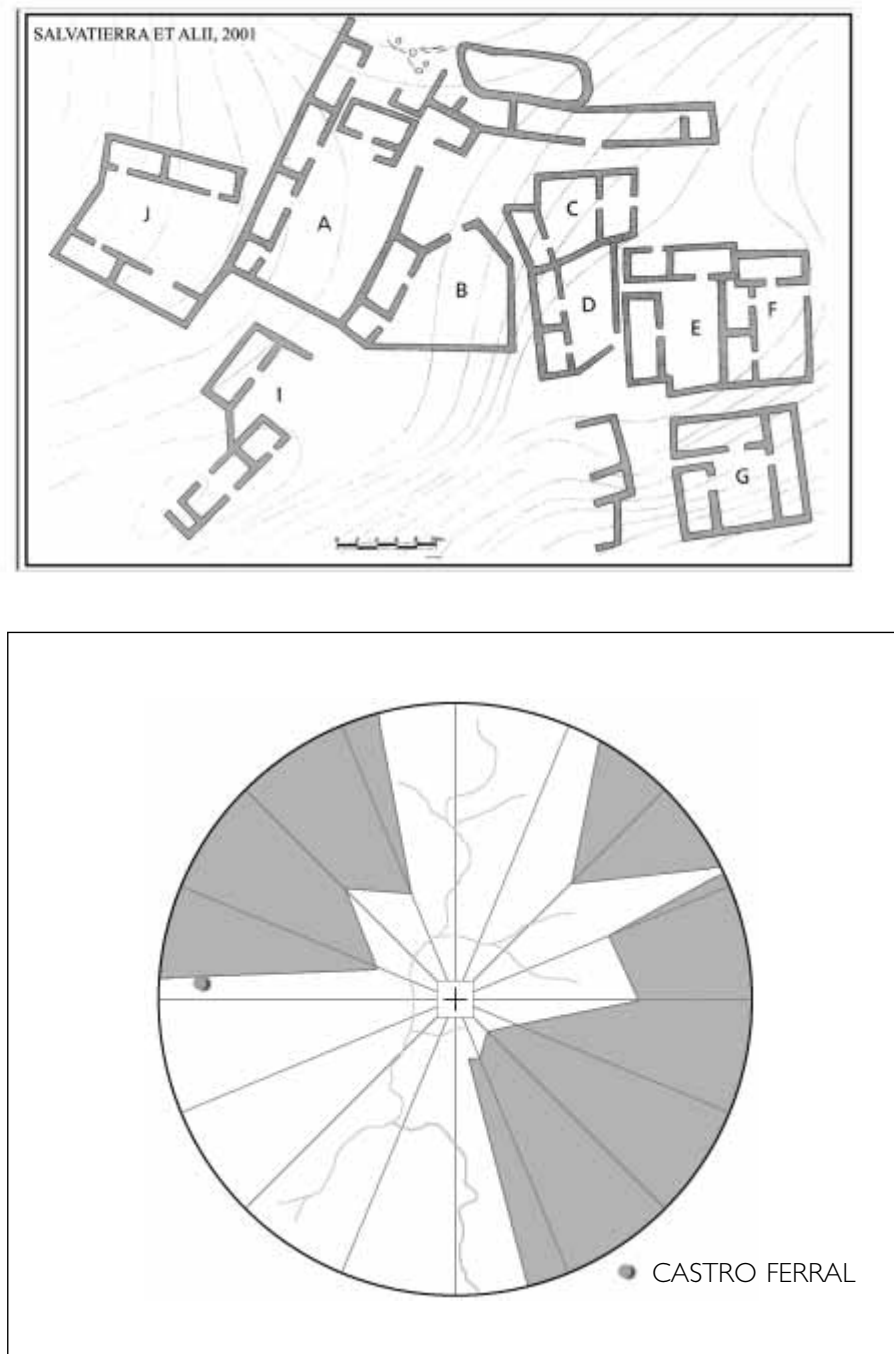


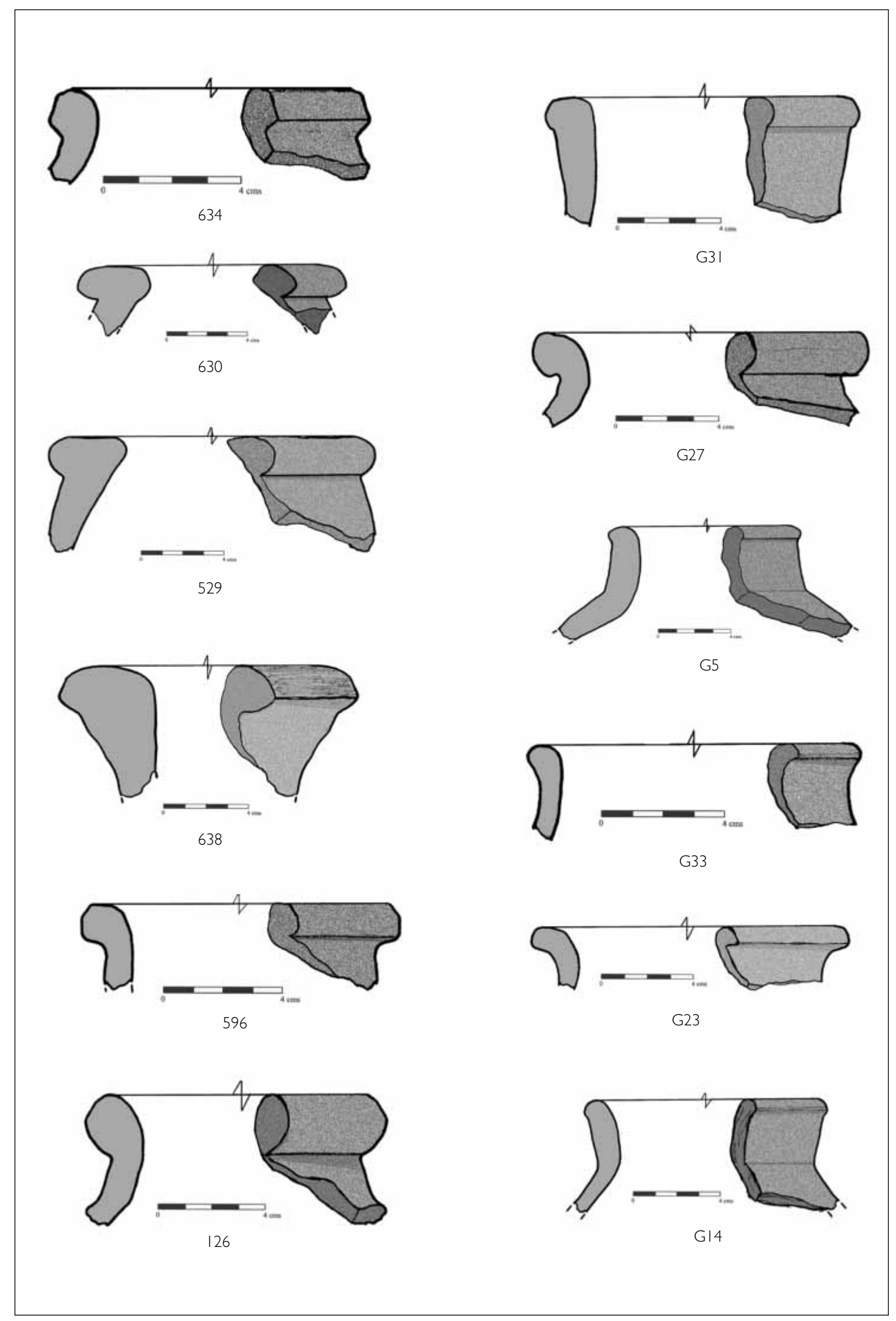

Fig. 5. Materiales cerámicos del Cerro del Castillo 

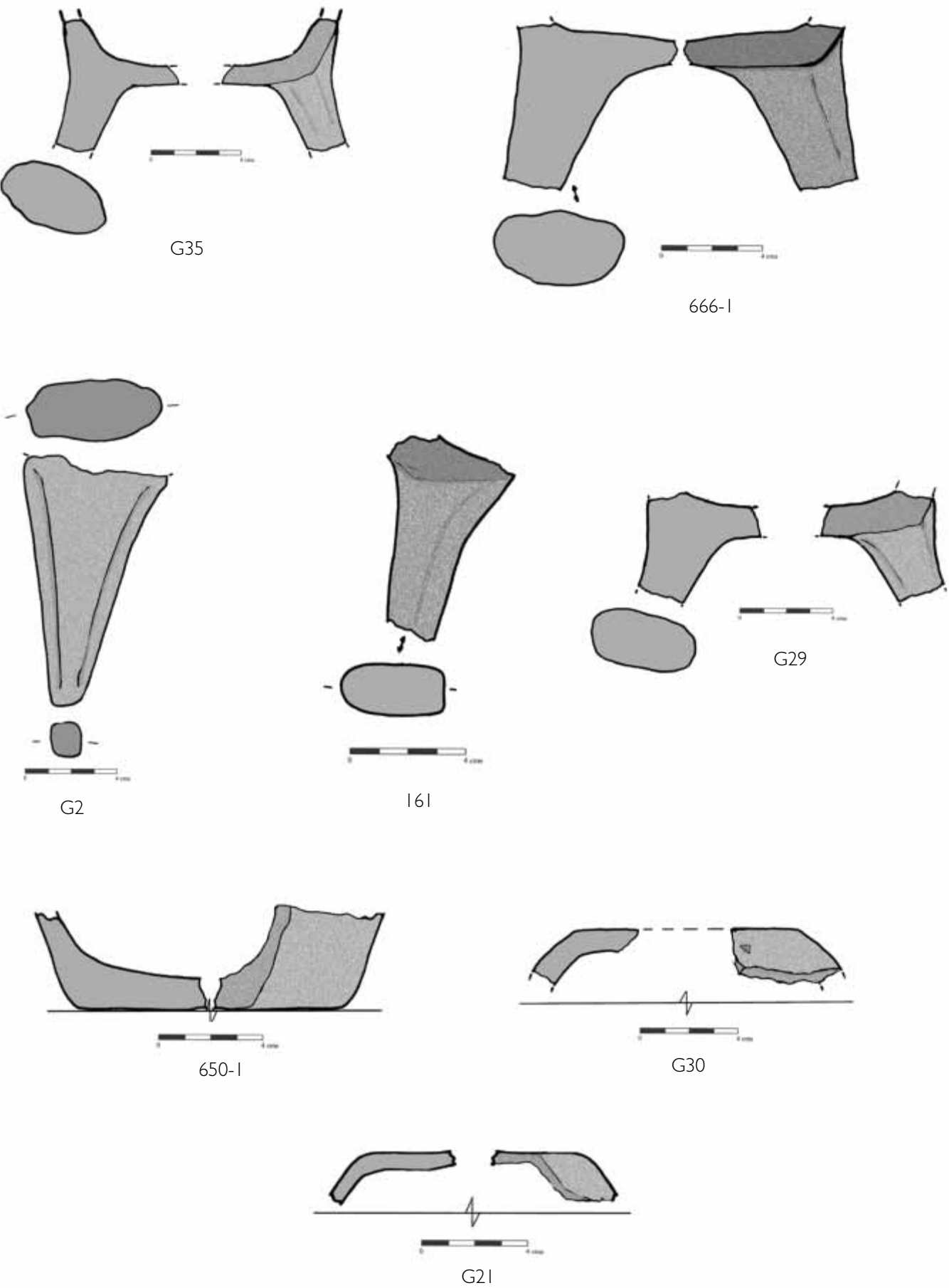

Fig. 6. Materiales cerámicos del Cerro del Castillo 


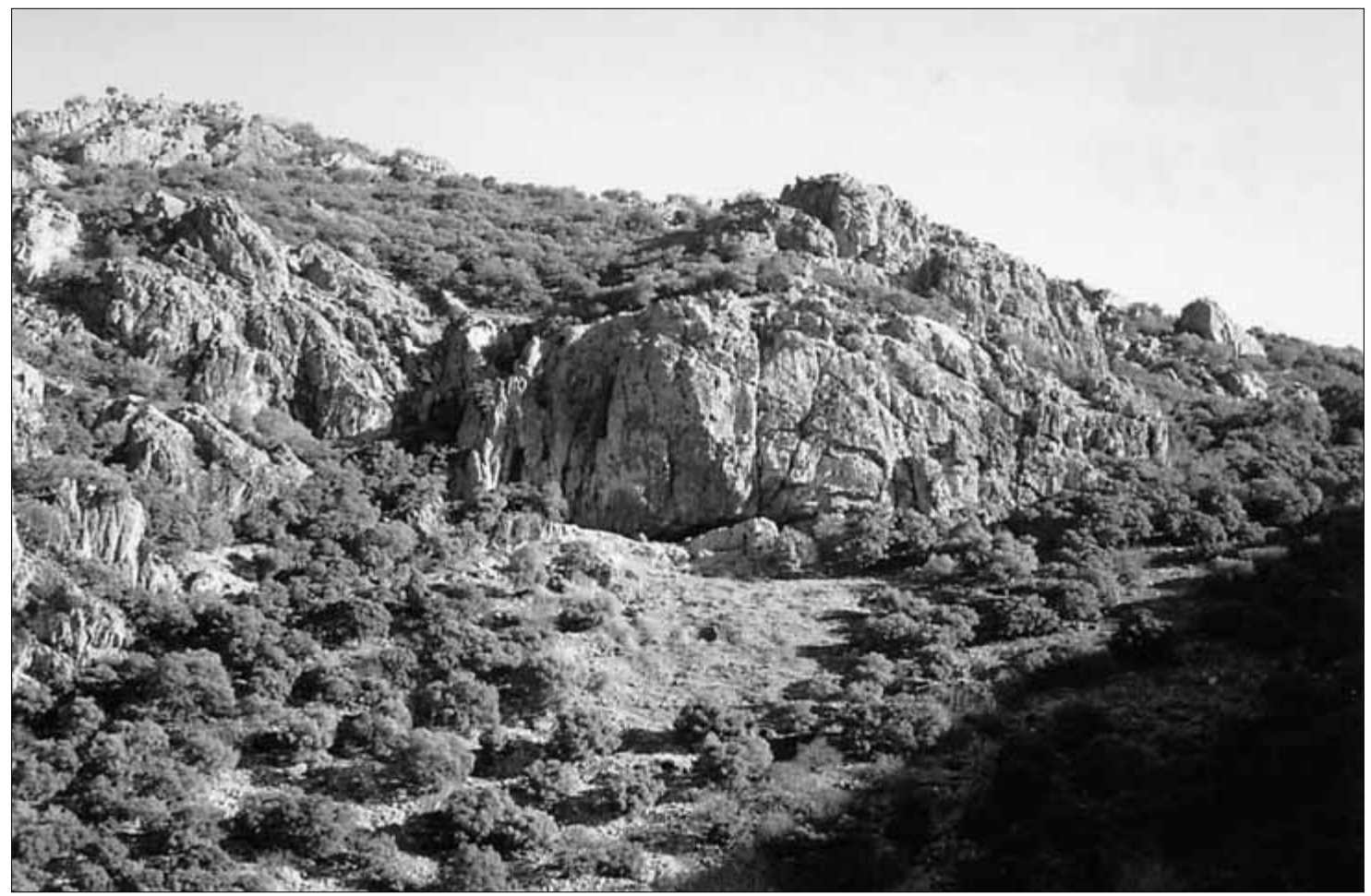

Lam. I. Vista general de la Cueva-Santuario del Collado de los Jardines

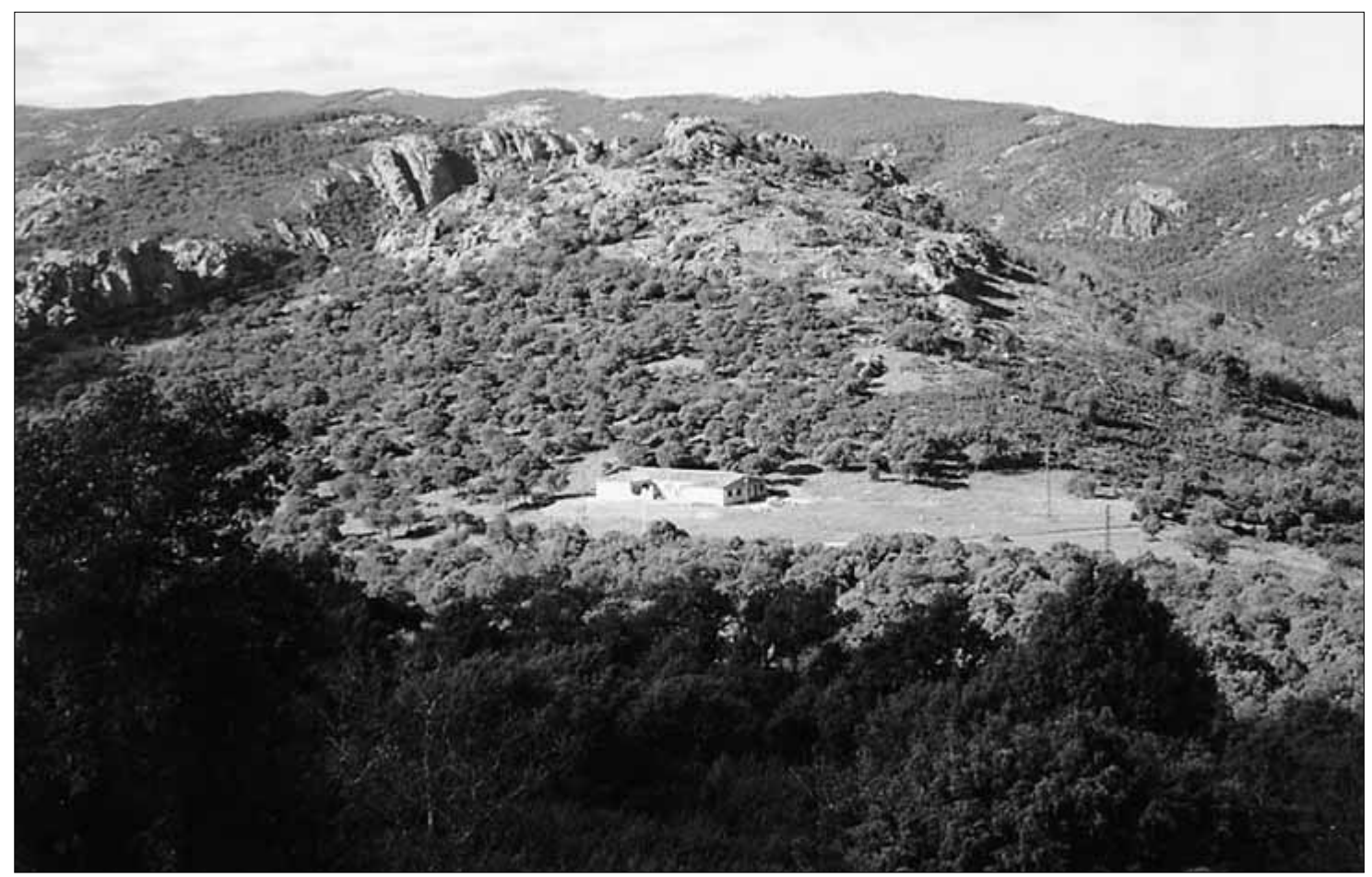

Lam. 2. Vista general de la Cueva-Santuario del Collado de los Jardines 


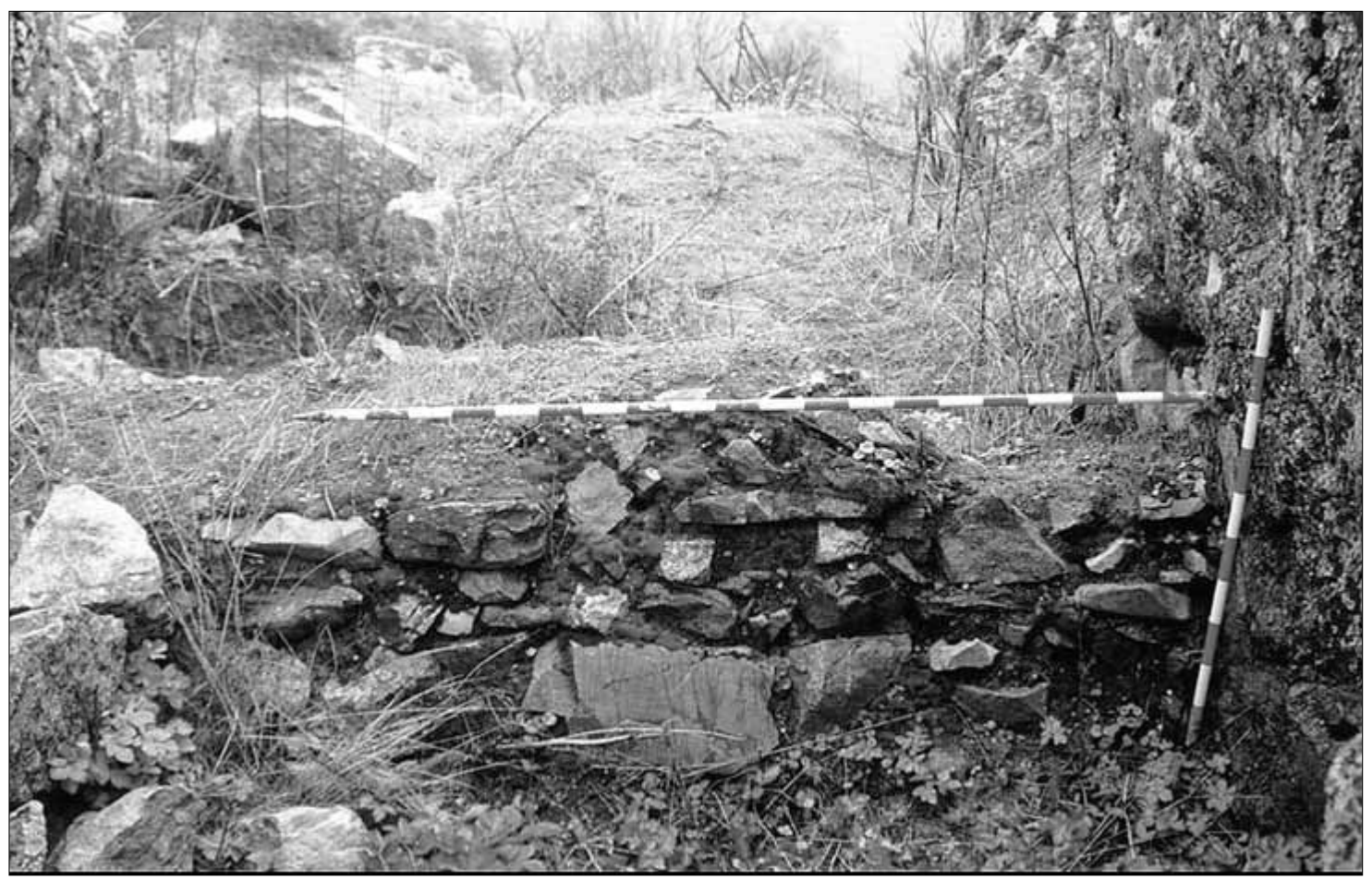

Lam. 3. Detalle de las estructuras en la cima del Cerro del Castillo

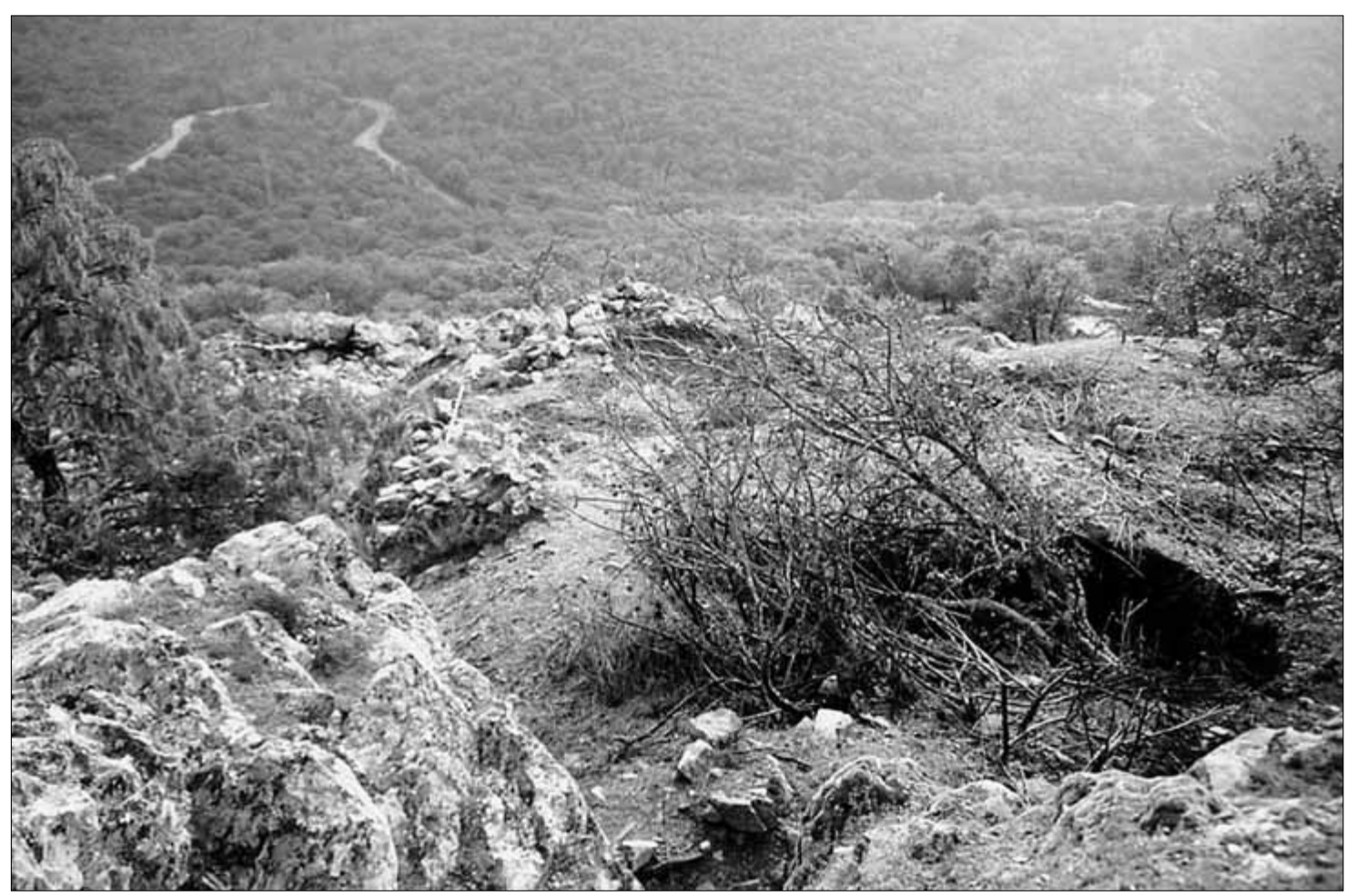

Lam. 4. Vista general de las estructuras en la ladera del Cerro del Castillo 


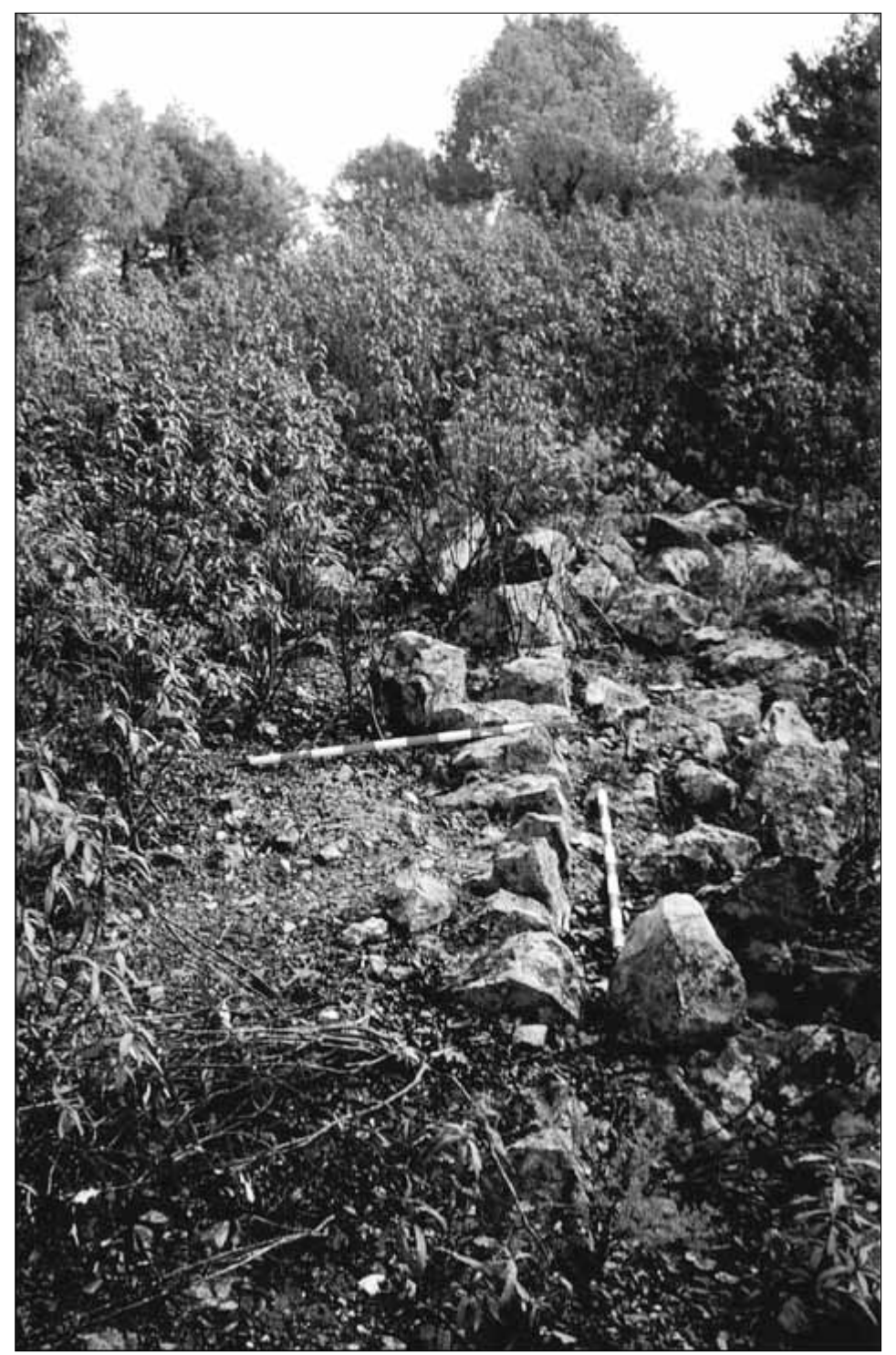

Lam. 5. Detalle del muro delimitador identificado como muralla del oppidum ibérico 